\title{
The Impact of Bus Door Crowding on Operations and Safety
}

\author{
Donald Katz and Laurie A. Garrow \\ Georgia Institute of Technology
}

\begin{abstract}
This study examines how bus design factors influence door crowding and quantifies how door crowding relates to operational performance and passenger safety. Results are based on data collected for 2,807 stops in Dhaka, Bangladesh. Door crowding is affected by multiple bus design factors, including door placement, aisle length, presence of a front seating area, and service type. Increases in door crowding are associated with longer marginal boarding times and an increased number of unsafe boarding and alighting movements that occur when the bus has not come to a complete stop. Results underscore the importance of educating conductors on the dangers associated with door crowding.
\end{abstract}

\section{Introduction}

Crowding within transit vehicles is an unstudied aspect of many systems. Although there is recognition that crowding by the door can affect operations and safety (e.g., many metro rail systems post "Do Not Stand in Doorway" signs), the underlying ways in which crowding affects operations and safety are not well understood. Crowded vehicles are a sign of healthy ridership, but regulating the extent to which vehicles get crowded may benefit passenger safety and vehicle performance at the curb. The Transit Capacity and Quality of Service Manual recognizes that in-vehicle circulation can be hindered by crowding, acknowledging that "boarding and alighting occurs more slowly when standees are present. The amount of space available 
for standees ... influence[s] how passengers circulate within the vehicle" (Kittelson \& Associates 2003).

The objectives of this study are to (1) investigate how bus design factors influence door crowding and (2) quantify how door crowding affects operational performance and safety. This study is unique in that it shows that crowding near door areas is the critical part of the internal space that affects operational performance.

\section{Background}

Dhaka's transportation system consists of a large number of modes that operate on infrastructure that does not meet the city's demand needs. Katz and Rahman $(2008,2010)$ describe the system in depth, noting the prevalence of non-motorized transportation and the role buses play in the population's mobility. The large majority of Dhaka's buses are privately-operated and carry the largest portion of motorized trips. Competition along routes is high, often with several operators from both "ticket" and "local" services. Ticket buses have one conductor who collects tickets at the door, and stops on the route are denoted by ticket sellers at tables. Local buses collect fares on-board with the use of two conductors; their stops are set but unmarked. For both bus services, the conductor chooses whether passenges are allowed to board and alight between stops. Local buses, for the most part, always allow this to occur between stops. Ticket buses are less likely to allow boarding and alighting between stops, but it does occur regularly.

Dwell time, which refers to time between the bus wheels stopping and starting, varies greatly on a conductor's desire to wait for passengers. The bulk of boarding and alighting activities, however, occurs at the beginning of the stop, and it is the variation in this portion of the dwell time that is studied in this paper.

Knowledge and insight into the transportation system of Dhaka comes from the first author's year on a Fulbright Scholarship in Dhaka. While there, he worked with Dr. Md. Mizanur Rahman at the Bangladesh University of Engineering and Technology and gained experience with the system by riding the bus system 10 hours each day.

\section{Literature Review}

This section describes Dhaka's bus system and summarizes key points from the literature related to how crowding occurs on buses, is typically measured, and affects operational performance. 
Dhaka is the largest urban area in Bangladesh and does not have an organized bus system or a rail mass transit system (Andaleeb et al. 2007). Dhaka's bus system, which is the primary public transportation mode for the city, is operated by dozens of private operators. City management has not provided the appropriate facilities for buses to operate, and the current number of operating buses does not meet passenger demand (Andaleeb et al. 2007). The lack of managerial oversight combined with unreliable schedules, unpublished time tables, and aggressive market competition have caused Dhaka's buses to become overcrowded (Zahir et al. 2000). Operators seek to maximize profits, which often results in long dwell times at major stops. In addition, operators often skip minor stops and/or do not come to a full stop at these locations for alighting passengers. Users and non-users alike indicate that these types of service deficiencies, particularly discomfort and congestion inside the bus, deter them from riding (Hoque and Hossain 2004). However, despite these complaints, Dhaka's buses still carry more than half of the passengers in motorized vehicles on Dhaka's streets (The Louis Berger Group 2005).

Crowding can make transit undesirable for passengers, even though a crowded bus indicates high levels of ridership (Perk et al. 2001). When passengers are unable to board or have difficulty boarding a bus due to overcrowding, the perceived quality of service is drastically decreased (Fernandez and Tyler 2005). Congestion inside the bus prevents passengers from being able to circulate freely for boarding, alighting, and finding a place to stand or sit (Fritz 1983). Some authors, however, have noted that the interior design of buses can be better designed to handle crowding so that it is more comfortable for passengers and reduces the serious negative effects (Kogi 1979).

Although operational performance can be influenced by multiple factors, several studies have noted that because human factors are too variable (such as conductor and driver behavior) and cannot be predicted for the future (Lin and Wilson 1992), it is better to look at aspects of transit operation that directly and predictably affect boarding and alighting rates, including crowding. For example, Kraft and Bergen's (1974) study is one of the first that found crowding inside vehicles had an effect on operations. They found that passengers boarding and alighting were often delayed, resulting in an increase beyond the transit vehicle's expected service time.

A variety of measures have been used to describe crowding and evaluate its effect on dwell time, but no universal measure has been developed to fully understand the effects of crowding on safety and operational performance measures. Examples of measures in the different studies include the gross number of passengers onboard (Zografos and Levinson 1986), the gross number of standing passengers (Lin 
and Wilson 1992), a "friction" factor based on the number of standing passengers (Dueker et al. 2004), a categorical measure of the volume (Fritz 1983) and load factors (Aashtiani and Iravani 2002; Rajbhandari et al. 2003). Load factor, however, which is often tracked by transit agencies, is not always effective in capturing what is occurring on-board because it relates to the number of seats and, thus, a large load factor could indicate a very crowded bus or a bus with few seats (Seattle DOT 2007). For this reason, measures that capture vehicle capacity based on both standing and sitting passengers who can safely and comfortable ride are generally considered to be more insightful.

Many of these studies noted above have found that as a bus becomes increasingly crowded, dwell times increase and passenger processing rates suffer, whether linearly or non-linearly. Crowding measures, however, are not always significant in explaining increases in dwell time, as seen in a study by Rajbhandari and colleagues (2003).

It is also important to note that in many studies, the impact of crowding on dwell times is not directly modeled but rather treated as an outlier or recording error. Crowding can be used to explain the existence of data outliers (Dorbritz et al. 2009). It has provided reason to remove data from a set because heavy crowding is considered more likely to be an error (Dueker et al. 2004).

In the context of our study, it is important to note that although door crowding has not been used as a measure to examine dwell times, several studies have indicated its importance. Fernandez et al. (2010) discuss that the number of passengers standing before the fare collection point inside the bus affects operations and make use of a dummy variable in dwell time models for when only the door area is free for standing. Zografos and Levinson (1986) recognized the importance of having ample space in the door areas and note that "even when the bus was full, the time per boarding passenger did not increase for the first two or three passengers, because the reception space was adequate." Our study expands upon this issue to create measures for crowded buses that capture this critical part of bus operations.

\section{Methodology}

This section describes the sampling frame, data collection methods, and the process used to identify observations that contained recording errors. This section also defines key terminology (e.g., early boards, late boards, door crowding). 


\section{Sampling Frame}

Data were collected within the city limits of Dhaka, Bangladesh, from March to August 2008. Seven bus types, displayed in Table 1, were sampled to investigate how service type, bus shape, door configuration, and front seating influence crowding. Buses that provide "ticket service" collect fares curbside; the ticket is subsequently collected by a conductor as the passenger boards the bus. In contrast, buses that provide "local service" collect cash fares on-board the bus once the bus is moving. Buses can be further classified into minibuses with one door, large buses with one door, or large buses with two doors. The placement of doors on large buses is also important in the context of crowding, as different crowding patterns may emerge depending on whether the rear door is placed in the middle or back of the bus. Some one-door buses have a front seating area adjacent to the driver's seat, generally reserved for female riders. The presence of a front seating area in the bus may also influence crowding.

Table 1. Sampling Characteristics

\begin{tabular}{|c|c|c|c|c|c|}
\hline \multicolumn{7}{|c|}{ Bus Designs } \\
\hline Bus Type \# & Service & $\begin{array}{c}\text { Bus } \\
\text { Shape }\end{array}$ & $\begin{array}{c}\text { Door } \\
\text { Configuration }\end{array}$ & Front Seating? & $\begin{array}{c}\text { \# Operators } \\
\text { Sampled }\end{array}$ \\
\hline Type 1 & Ticket & Large & One door & Yes & 3 \\
\hline Type 2 & Ticket & Large & One door & No & 3 \\
\hline Type 3 & Ticket & Large & Two doors (front/middle) & No & 3 \\
\hline Type 4 & Ticket & Large & Two doors (front/back) & No & 3 \\
\hline Type 5 & Ticket & Minibus & One door & Yes & 3 \\
\hline Type 6 & Local & Large & Two doors (front/back) & Yes & 1 \\
\hline Type 7 & Local & Minibus & One door & Yes & 7 \\
\hline
\end{tabular}

The majority of Dhaka's bus system is operated by private companies. The Bangladesh Road Transport Corporation is responsible for issuing route permits to private operators. The permits dictate the route assigned to the bus; however, route numbers are often not visible to the waiting passenger. In addition, maps and timetables are rarely available, and headways are seldom consistent for a given route. Competition among operators on routes is high, and drivers compete with other buses, including those from the same company, to collect passengers. Between the origin-destination pair of Mohammedpur and Gulistan, for example, five ticket buses and two local buses are operated. 
Because there are hundreds of private operators, a stratified sampling frame was used in the study. The number of bus operators sampled for each bus type is shown in Table 1. For each operator, a route was observed six times (three times in each direction). Data were collected on weekdays when buses were crowded.

\section{Data Collection}

Data were collected by an observer on-board the bus who used a voice recorder. Boarding and alighting times were recorded for each passenger, as well as information on which door he/she used and at which stop the passenger movements occurred. Information on boarding and alighting times was used to calculate the total number of passengers on the bus and the time between passenger boarding and alighting movements. After all buses were ridden and all stops on each route were sampled, data had been collected for 147 bus routes and 2,807 stops.

Several operating and safety characteristics were also recorded for each bus stop. After a bus had left a stop, the number of passengers standing in the door areas of the bus was recorded. These door areas are displayed in Figure 1 and include the number of passengers standing before the front row (BFR) and the number of passenger standing in front of the back door (FBD). Any passengers sitting in a front seating area on a bus were excluded from the BFR value, as noted in the figure. The distance the bus stopped from the curb, measured in half-lane increments, was also noted for each stop. Unsafe boardings and alightings, which occurred when a bus was not fully stopped, were recorded and classified into four variables: early boards (EB), early alights (EA), late boards (LB), and late alights (LA).

As seen in Figure 2, a bus's "stop" was defined from the point in time in which it entered the stop area-even while still moving - to its first gear change upon leaving the stop. The dwell time begins when wheels stop and ends when wheels start (and the bus actually departs from the stop location, i.e., as shown in the figure, there were cases in which a bus would start to move, then stop again to wait for additional passengers). LA and LB occur from the time period in which a bus departs the stop until the stop break point. The stop break point was defined to be (1) the point immediately after the next intersection or (2) the time at which the bus was moving at full speed. The total number of BFR and FBD are tallied at the stop break point, and any boarding and alighting after this point in time were classified as EA and EB for the subsequent stop. 


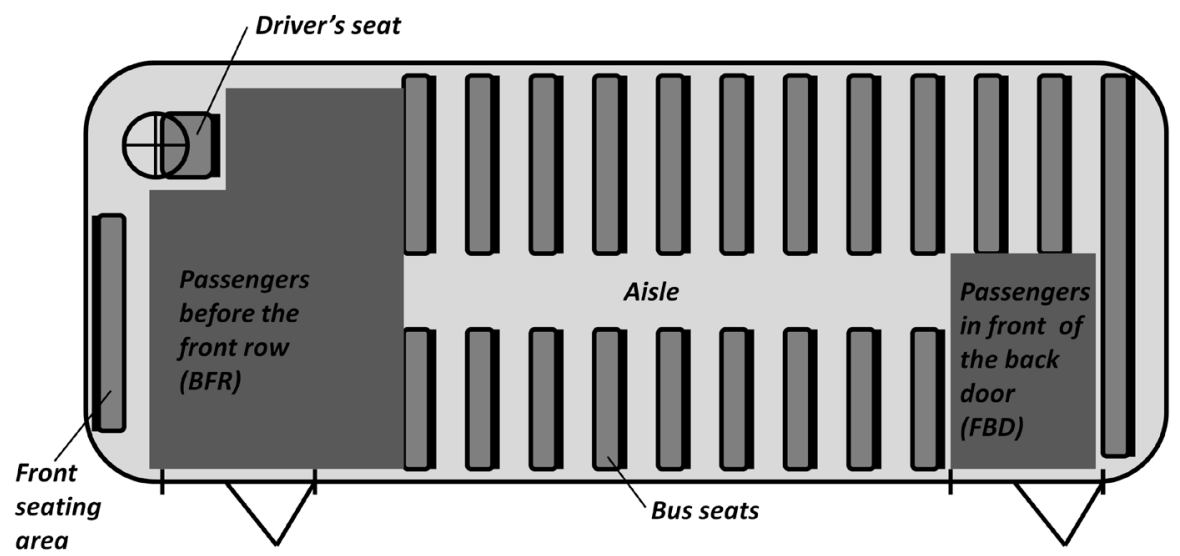

Figure 1. Location of BFR and FBD variables within a bus design

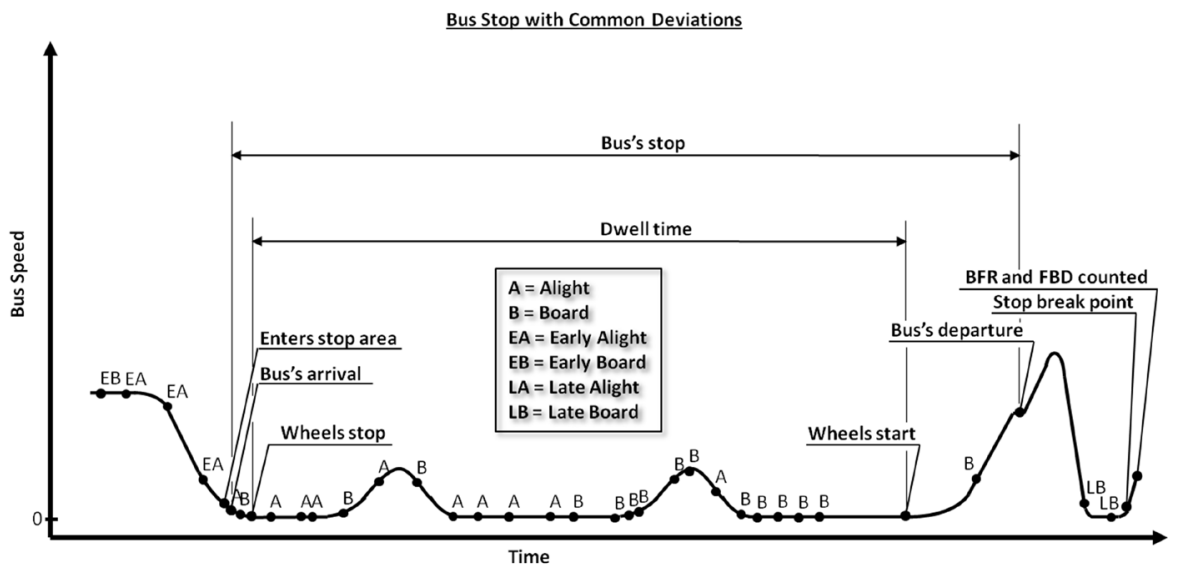

Figure 2. Typical bus stop with different passenger movements noted, time points, and key time durations

\section{Definitions for Door Crowding and Marginal Boarding and Alighting Times}

Door crowding is the key variable in this study. Several measures, including load factors, that have been used in prior studies do not target the biggest issue in bus crowding - the congregation of crowds around the doors that creates an impedance for passengers boarding and alighting. Thus, this analysis creates new measures of crowding that can more effectively assess this important aspect. In this study, door crowding is discussed in terms of (1) the gross number of riders 
standing in the door areas and (2) the percentage of standing passengers who locate near doorways.

To assess performance, marginal passenger boarding and alighting times are used. In previous studies, it was common to separately assess marginal boarding times and marginal alighting times for buses. In Dhaka, however, the pushing and shoving that often characterizes the simultaneous boarding and alighting passengers requires a measure that captures the interaction between these two activities.

The combined marginal time for boarding and alighting passengers is calculated by considering only stops for which the buses came to a full stop for passengers to board and alight. The dwell time is calculated from the first board or alight after the wheels stop. In addition, because some buses dwell for many minutes to wait for additional passengers, only the first portion of the stop with the busiest activity was used. After 10 seconds of no boardings or alightings, the bus stop was considered "finished," and the marginal boarding and alighting time was measured only for this initial period. Engineering judgment was used to choose this cutoff value and is acknowledged as a limitation to this study. The joint marginal boarding and alighting times is calculated by dividing the length of effective dwell time by the number of boarding and alighting passengers during the defined boarding and alighting period.

\section{Elimination of Recording Errors}

In the process of collecting the data, recording errors may have been introduced. These recording errors were identified by comparing the observed on-board number of BFR and FBD passengers to the number of standing passengers calculated from recorded boarding and alighting movements. The key assumption used in this comparison is that passengers desire to sit on the bus until there are no seats left available. This assumption is considered reasonable, as Bangladeshi passengers were observed to be aggressive in finding seats.

When the total number of BFR and FBD is greater than the number of standing passengers, it was assumed that a recording error had occurred because passengers could be standing outside the door areas in the aisles. To create a "cleaned" dataset that removed these recording errors, observations were deleted if they exceeded one of two error thresholds: (1) the difference between BFR + FBD and standing passengers was four passengers or more or (2) the difference was greater than 15 percent of the total number of passengers on the bus. Both of these thresholds were chosen through engineering judgment, because no established threshold 
existed for cleaning the differences between observed and calculated passenger quantities. Application of these thresholds removed less than 4 percent of the 2,807 stops, leaving 2,703 bus stops in the "cleaned" dataset.

\section{Analysis}

The analysis is split into three parts that look at the various ways bus design affects crowding, and how the crowding then affects the service and safety of buses.

\section{Bus Design and Crowding}

Bus design factors, such as the presence of a front seating area, number and placement of doors, aisle length, and fare collection method (on-board or off-board payment), may influence how riders crowd within a bus. The relationships among bus design factors and the percentage of standing riders who crowd near doors is of particular interest, as this could result in longer dwell times and safety issues. That is, bus crowding near the doorways likely has a greater impact on operational performance and safety measures than crowding in the aisles because door crowding directly affects passengers attempting to board and alight.

In this section, door crowding as a percentage is examined as a function of the load factor of the bus right after it leaves a stop. Bus stops are defined as the unit of analysis, and all bus stops from the cleaned dataset are used. Defining crowding characteristics at the stop level, as opposed to a route level, allows examination of how crowding happens within the bus and how crowding relates to stop characteristics and dwell times.

The Transit Capacity and Quality of Service Manual (TCQSM) uses load factor to define different levels of service (LOS) within a transit vehicle (Kittelson \& Associates 2003). Buses with standing passengers include LOS D (load factors between 1.0 and 1.25), LOSE (load factors between 1.26 and 1.5), and LOS F (load factors greater than 1.5). The TCQSM does not define LOS as a function of crowding around the doors, but the relationship between the two gives indication as to how different levels of crowding interact with bus design factors.

The existence of a front seating area near to the driver is associated with more riders standing near the front door when the bus is very crowded. A comparison between bus type 1 and bus type 2, identical except that bus type 1 has a front seating area, shows that the impact of a front seating area occurs when buses operate at LOS E and F. At these high levels of crowding, buses with a seating area 
have a significantly greater proportion of stops in which the majority of standing passengers are near the door (59\% vs. $29 \%$ ). A Chi-square analysis provides further evidence of different door crowding levels when these buses operate at LOS $E$ or $F$ $\left(\hat{\chi}^{2}=5.3>\chi_{1,0.05}^{2}=3.8\right)$.

Two-door bus configurations vary in the physical location of their doors. Bus type 3 places doors at the front and middle of the bus, while bus type 4 has its rear door in the back of the bus. These different configurations result in distinct door crowding characteristics. Buses with front/middle designs have more crowding than buses with front/back designs. On average, 84 percent of standing passengers locate near doors on front/middle bus designs, compared to just 50 percent on buses with front/back designs. For the front/middle bus design, there are a large number of stops, with almost all standing passengers congregating near the door, even when load factors are high. A Chi-square analysis provides evidence that buses with front/middle door designs are associated with higher levels of door crowding $\left(\hat{\chi}^{2}=20.0>\chi_{1,0.00001}^{2}=19.5\right)$.

Aisle length also affects door crowding standing. A comparison is made between bus type 5 and bus type 1, similar except for their aisle length. It is seen that buses with shorter aisles are almost twice as likely to have the majority of standing passengers near the door when compared to buses with long aisles. A Chi-square analysis further confirms that short aisles are associated with a higher level of door crowding $\left(\hat{\chi}^{2}=25.0>\chi_{1,0.00001}^{2}=19.5\right)$.

Ticket (bus types 1-5) and local buses (bus types 6-7) both are prone to have standing riders congregating by doors. On average, 59 percent of standing passengers locate near doors on ticket buses compared to 66 percent on local buses. This average is significant at the $95 \%$ confidence level $\left(\hat{t}=3.32>t_{1072,0.05}=1.65\right)$, but no clear differences emerged when different load factors were examined. Overall, local buses are crowded more often than ticket buses; however, when these buses are crowded, it appears that patrons on both ticket and local buses crowd in a similar fashion by the doorways.

Results indicate that doors are a popular place to crowd. Regardless of the crowding level on a bus, it is expected that approximately two-thirds of standees will wait near the door(s). Thus, even at low levels of crowding, doorway crowding occurs at a high rate. In turn, these high levels of door crowding can impact operational performance and safety measures, as discussed in the next sections. 


\section{Operational Performance and Crowding}

Crowding around the doorways of a bus directly affects operations because passengers must push through a mass of people when boarding and alighting. In this part of the study, the gross number of passengers standing by the door is used to assess door crowding, measured at the stop level. One-door buses are analyzed statistically, whereas two-door buses (whose operations are affected by factors not recorded in the database) are described qualitatively.

In this section, BFR is adjusted to represent the effective BFR when the bus actually arrives at the stop (since BFR is noted immediately after the previous stop). This is determined by subtracting any alights (LA and EA) and adding any boards ( $L B$ and EB) between the two stops.

Increased crowding by the doorway results in longer joint marginal passenger boarding and alighting times. The crowding level near the doorway is stratified into three bins: no crowding (0 passengers before the front row [BFR]), low crowding (1-9 passengers BFR), and high crowding (10+ passengers BFR). As seen in Table 2, the mean marginal passenger boarding and alighting time increases approximately 25 percent across the three crowding levels, although it must be noted that the standard deviations are larger than the differences.

Table 2. Marginal Passenger Boarding and Alighting (B/A) Times for Different Levels of Door Crowding

\begin{tabular}{|c|c|c|c|}
\hline Crowding Level (BFR) & Mean B/A Time (sec) & Std. Dev. B/A Time (sec) & Count (\# stops) \\
\hline 0 & 2.33 & 1.15 & 515 \\
\hline $1-9$ & 2.54 & 1.33 & 466 \\
\hline $10+$ & 2.90 & 1.41 & 219 \\
\hline
\end{tabular}

The distributions of these three levels of crowding are shown in Figure 3. Buses with more crowded doorway areas tend to have higher average marginal B/A times. A Chi-square analysis further confirms the differences in these distributions $\left(\hat{\chi}^{2}=\right.$ $57.0>\chi_{24,0.0005}^{2}=53.4$ ). 


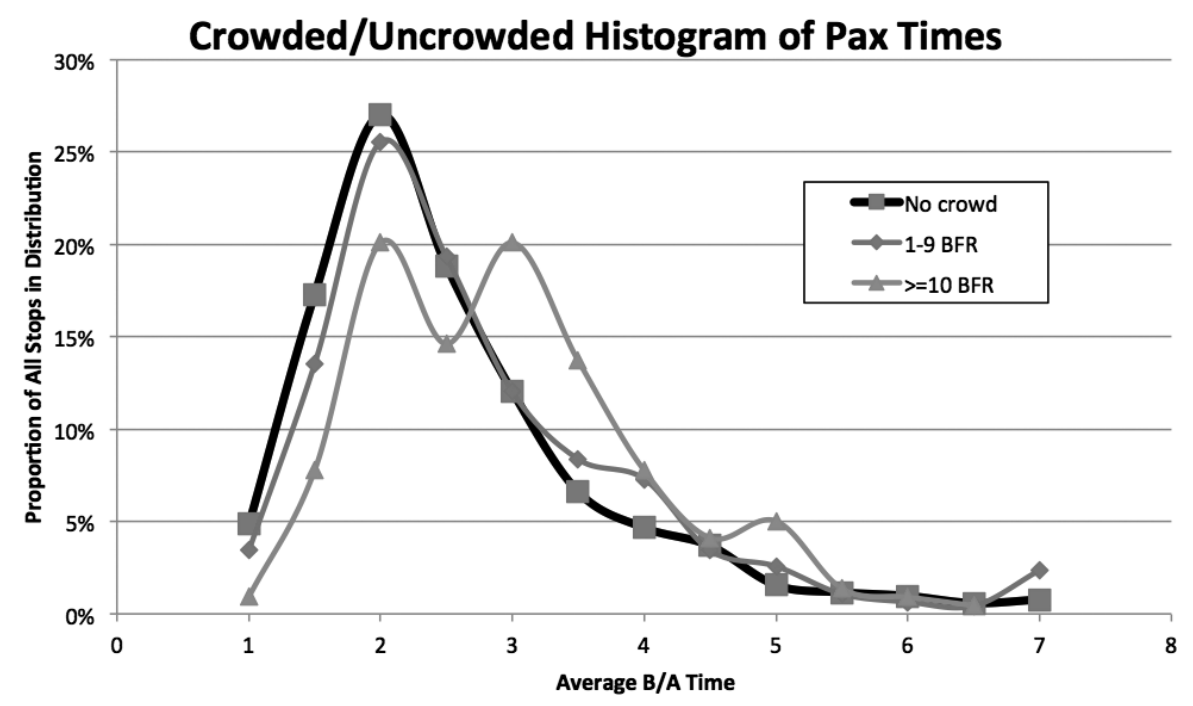

Figure 3. Distribution curves of marginal boarding and alighting time at a stop for the three levels of crowding

Viewed by different levels of crowding by the door, as in Figure 4, the growth of marginal passenger boarding and alighting times increases nonlinearly as the number of passengers by the door increases. Although the standard deviation bars overlap with the uncrowded bus marginal time, the results provide a directional understanding of the relationship between door crowding levels and marginal boarding and alighting times.

To ensure that the results shown in Figure 4 were not influenced by the number of passengers boarding and alighting at a stop, the latter was used as a control variable. The gross combined level of boardings and alightings at a stop was used because it is consistent with the measure of a combined marginal dwell time defined earlier. The aim was to ensure that crowded buses were not dwelling longer per passenger due to the volume of operations occurring at the stop. Table 3 shows that for different levels of boarding and alighting at a stop, a more crowded bus takes longer per passenger. In addition, as the total number of boardings and alightings increases, the marginal boarding and alighting times decrease, which is consistent with prior findings reported in the literature (Guenther and Sinha 1983). Efficiencies are gained with more passenger movements at a stop. 


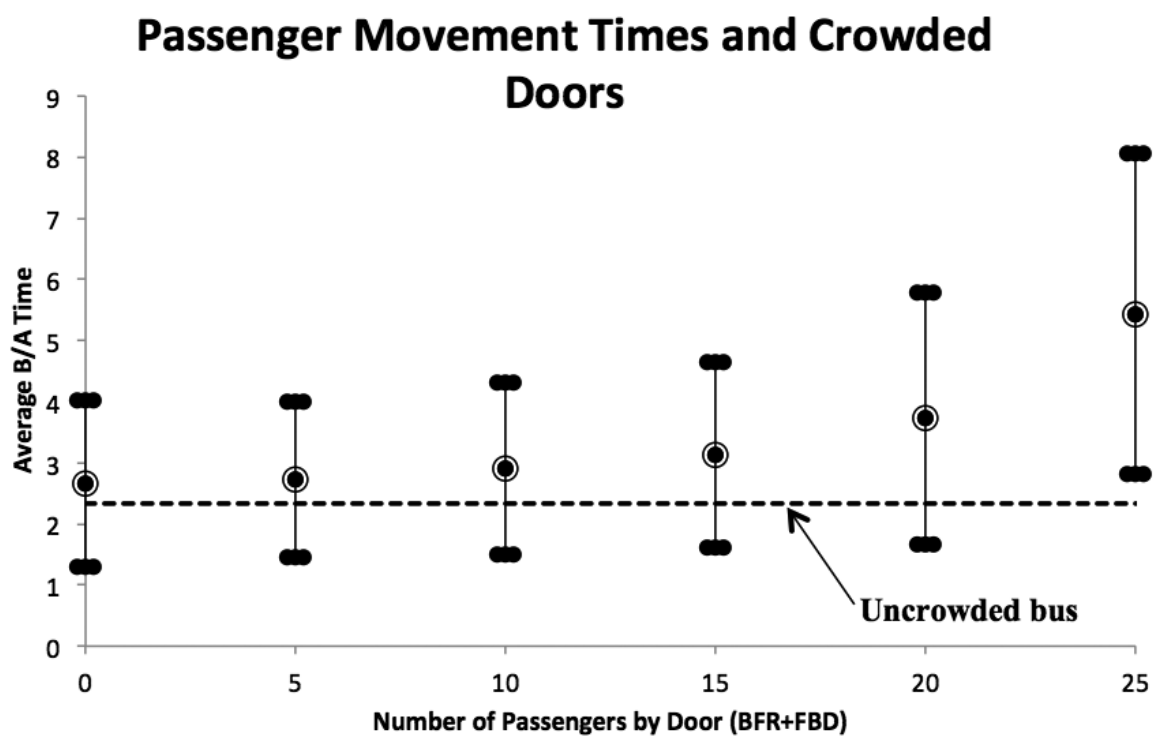

Figure 4. Increase in marginal passenger boarding and alighting times as doorways get more crowded

Table 3. Relationship among Volume of Boardings and Alightings, Crowding Level, and Marginal Boarding and Alighting Times

\begin{tabular}{|c|c|c|}
\hline Boardings + Alightings & Crowding Level & Marginal Boarding and Alighting Times (sec) \\
\hline \multirow{3}{*}{$2-5$} & 0 & 2.42 \\
\cline { 2 - 3 } & $1-9$ & 2.73 \\
\cline { 2 - 3 } & $>10$ & 3.24 \\
\hline \multirow{4}{*}{$6-10$} & 0 & 2.32 \\
\cline { 2 - 3 } & $1-9$ & 2.52 \\
\cline { 2 - 3 } & $>10$ & 2.90 \\
\hline \multirow{3}{*}{$11-24$} & 0 & 2.05 \\
\cline { 2 - 3 } & $1-9$ & 2.18 \\
\cline { 2 - 3 } & $>10$ & 2.48 \\
\hline \multirow{3}{*}{$>25$} & 0 & 1.85 \\
\cline { 2 - 3 } & $1-9$ & 1.88 \\
\cline { 2 - 3 } & $>10$ & 2.11 \\
\hline
\end{tabular}


The results for one-door buses are clear, because all one-door buses operate with a single conductor and all passengers have to push through the same crowd at the front bus door to board and alight. Extending the analysis to two-door buses is much more complex because of their distinct designs and operations. For example, bus type 3 operates distinctly from other bus types because it has a middle door, and often the single conductor creates an internal flow with a front boarding and back alighting door. Similarly, even though bus types 4 and 6 both have front/back configurations, the latter has two conductors, which greatly influences how door crowding and curbside operations occur. Because of the interactions among conductors, bus designs, and internal flows, it was difficult to create robust relationships between bus crowding and boarding and alighting times for two-door buses (as the database did not record conductor behavior).

\section{Linear Regression Models}

Linear regression models were used to examine the combined impacts of the number of boardings and alightings, crowding measures, load factors, vehicle design characteristics, and fare payment type on marginal boarding and alighting times. Results for two models are shown in Table 4. Results show estimated changes in marginal dwell times for a marginal change in the respective variables. All variables are significant at the 0.05 level except LOS D in Model 2.

\section{Table 4. Linear Regression Results for Marginal Dwell Times}

\begin{tabular}{|l|c|c|}
\cline { 2 - 3 } \multicolumn{1}{c|}{} & Model 1 & Model 2 \\
\hline Intercept & $2.450(35.67)$ & $2.398(32.88)$ \\
\hline LOS D & $0.201(2.41)$ & $0.127(1.40)$ \\
\hline LOS E & $0.345(3.95)$ & $0.279(3.01)$ \\
\hline LOS F & $0.617(6.57)$ & $0.551(5.58)$ \\
\hline \% of Standing Passengers by Door &.- & $0.180(2.11)$ \\
\hline \# of Boards and Alights & $-0.029(-7.40)$ & $-0.030(-7.49)$ \\
\hline Ticket Bus & $0.395(4.45)$ & $0.414(4.64)$ \\
\hline Large Bus & $-0.331(-3.83)$ & $-0.321(-3.71)$ \\
\hline Adj. R2 & 0.060 & 0.062 \\
\hline
\end{tabular}

Key: Parameter estimate (t-statistic). NOTE: LOS D is included to show non-linearity of increases in load factor from LOS D to LOS F, even though it is not always significant (as in Model 2).

Model 1 shows a linear regression using load factors, as represented through LOS dummy variables to describe how crowding affects marginal dwell time. The addi- 
tion of a spatial crowding measure-the percentage of standing passengers located near doorways-improves the model fit. This is important because it shows that crowded buses can reduce their dwell times by conductors encouraging passengers to stand in the aisle. The boarding and alighting passengers regression coefficient indicates how each additional passenger reduces marginal dwell time.

Ticket buses have longer marginal dwell times than local buses, likely due to the need to collect tickets while boarding, but also the lower likelihood of passengers pushing and shoving when boarding the bus. The orderly boarding process adds to the bus's dwell time. Among bus design characteristics examined (bus size, number of doors, front seating area, location of second door on two-door bus), only the variable for large vs. minibuses was significant. Large buses have shorter marginal dwell times because standing passengers have more room to spread out in the bus and do not need to stand by the door.

\section{Safety and Crowding}

Safety on buses focuses on several aspects. When crowded, riders often are forced to hang out of the door frame, wedging their foot onto the first step and grasping onto some piece of the bus. Buses often do not stop completely at a designated stop, choosing rather to roll through at a low speed to save time on their route. Passengers sometimes board and alight between stops, either when the bus is caught in the middle of traffic or when it is slowing down to make a turn. In this section, crowded buses are assessed to see if they influence these safety factors in a negative way. Crowded and uncrowded buses were compared using the cleaned dataset with all bus stops, except for the hanging out the door analysis. For examining passenger hanging out the door, only buses that have one or more passengers standing at the stop are used.

Crowding within a bus increases the possibility that passengers will hang out the door. Figure 5 shows the proportion of stops with passengers hanging out the door as well as the "conditional" average number of passengers hanging out the door. The latter is "conditional" in the sense that it includes only those stops for which at least one passenger is hanging out the door. As seen in Figure 5, higher load factors are associated with more passengers hanging out the door. In general, buses with load factors of LOS D and above do not have passengers hanging out the door. Two-door buses are more likely to have passengers hanging out the door $(19.4 \%$ vs. $12.0 \%)$. 
(a) Local 1-door bus

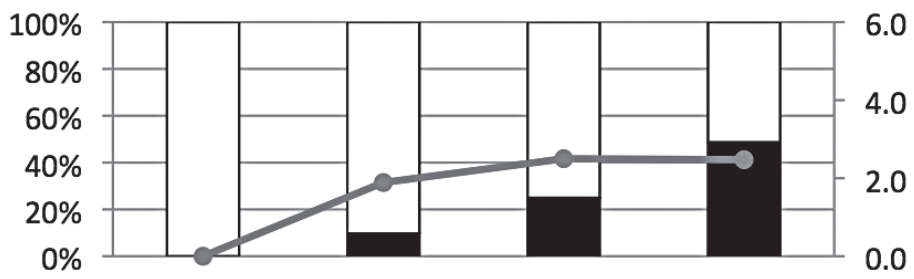

(b) Ticket 1-door bus

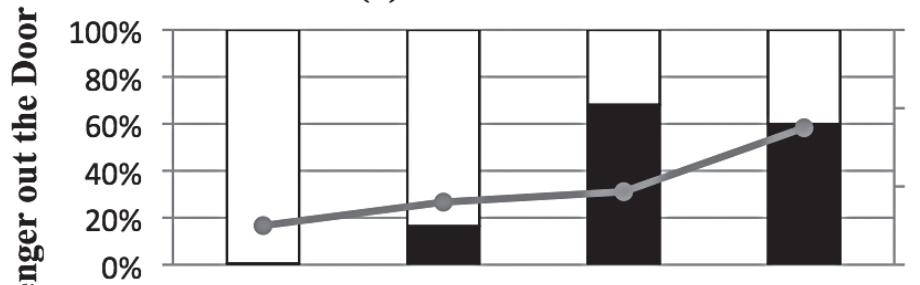

(c) Local 2-door bus

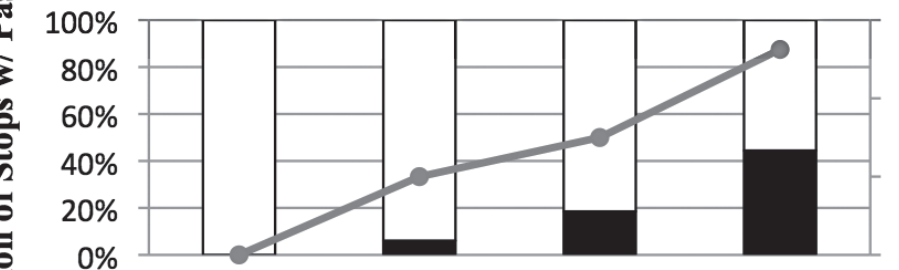

(d) Ticket 2-door bus

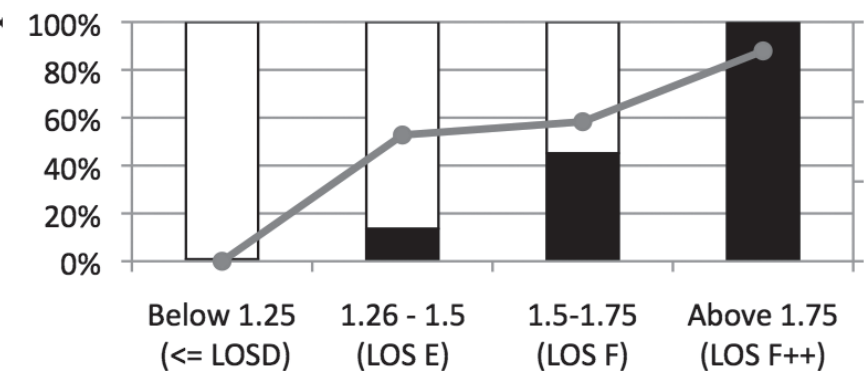

\section{Load Factor}

$\square$ Not out door $\square$ Out door $\multimap-\#$ pax out door (conditional distribution)

Figure 5. Analysis of passengers hanging out the door as a function of load factors

Figure 5 also displays the effect that load factors have on the number of people hanging out the door. As load factors increase, the frequency of stops with passengers hanging out the door increases. In addition, higher load factors are associated 
with a greater average number of passengers hanging out the door. Two-door buses have larger averages because there are two doors at which passengers out the door are tallied.

There is a strong relationship between the number of passengers standing near the doorway of a bus and the number of passengers who are forced to hang out the door. For one-door buses, the correlation is 0.585 , whereas for two-door buses the correlation is 0.708 . Thus, as the number of riders standing near the doors increases, so does the number of passengers hanging out the door.

Buses that roll through a bus stop put passengers at risk by forcing them to jump and run when alighting or run and jump when boarding. Uncrowded buses are more likely to roll through a stop than crowded buses; 9.5 percent of uncrowded buses roll through bus stops as compared to 5.6 percent of crowded buses. A Chisquare analysis confirms this difference $\left(\hat{\chi}^{2}=12.7>\chi_{1,0.0005}^{2}=12.1\right)$. An alighting passenger is more at risk for a bus to roll through the passenger's bus stop than a boarding passenger for both uncrowded and crowded buses.

Unsafe boardings and alightingss occur between stops and, thus, put passengers at risk because other road users do not expect passengers to be boarding and alighting a bus at these locations. As seen in Table 5, crowded buses have higher rates of unsafe boardings and alightings. For different door crowding levels, it is seen that buses with higher volumes of crowding near the door have greater rates of early boards (EB), early alights (EA), late boards (LB), and late alights (LA). Significant to note is that the percentage of early and late boardings on crowded buses is nearly double those seen on uncrowded buses.

\section{Table 5. Percentage of Bus Stops at Different Door Crowding Levels that had Unsafe Boardings and Alightings}

\begin{tabular}{|c|c|c|c|c|}
\hline $\begin{array}{c}\text { Crowding } \\
\text { (BFR and FBD) }\end{array}$ & EB (\%) & EA (\%) & LB (\%) & LA (\%) \\
\hline 0 & 8.6 & 29.4 & 5.1 & 2.9 \\
\hline $1-9$ & 14.6 & 38.6 & 10.6 & 5.2 \\
\hline$>10$ & 19.7 & 34.3 & 10.7 & 3.9 \\
\hline
\end{tabular}

The phenomenon of crowded buses leading to greater rates of unsafe boardings and alights is likely due to conductors and drivers eager to raise revenue. Based on observations in the field, operators who aim to crowd their bus are also more likely to allow passengers to board between stops to garner additional ticket fares. 
This creates the appearance that crowded buses have a greater likelihood of these operations, but the cause is more likely operators allowing this unsafe behavior. EB and LB have greater increases because operators are more likely to allow a potential rider to board between stops because it means more profit and less likely to allow a rider to alight between stops because it slows down operations and does not benefit their profit margin (the rider is already on board). In addition, it is less likely for an alighting passenger to push through a crowd at the door to alight between stops, whereas a potential boarding passenger does not perceive the crowded bus as an obstacle to boarding.

Buses in Dhaka are prone to stop farther than one lane from the curb and sometimes in the middle of the traffic stream, two to three lanes out. On average, uncrowded buses stop about half of the time within one lane of the curb, uncrowded buses slightly less often. The crowded buses' slightly higher frequency of stopping farther than one lane from the curb, however, is not statistically significant. Thus, both crowded and uncrowded buses operate in an unsafe manner when stopping at a bus stop.

\section{Conclusion and Recommendations}

The results of the study are summarized in Table 6. The main contribution of the paper is that it is one of the first papers that quantifies the relationship between marginal dwell time and door crowding; to the authors' knowledge, this is the first time this relationship has been explicitly quantified in the literature. This paper is also one of the first to show that certain bus design factors influence where passengers decide to stand-depending on aisle length, service type, the presence of front door seating, and the location of the back door on two-door buses, door crowding can be more prone to occur. Linear regression was used to show that this increased door crowding is a significant factor in increasing marginal dwell time. Through on-board observations, it was seen that door standing is preferred because it gives a passenger easy access to get off the bus; however, it causes the most issues for all other passengers.

This paper is also one of the first to explore the relationship between safety and crowding. We find some evidence that unsafe passenger behavior is amplified in crowded buses. Crowded buses increase passenger risk because crowding tends to occur most often at doorways. It is associated with unsafe boarding and alighting movements and passengers hanging out the door. Unsafe boardings increase 
Table 6. Summary of Key Findings

\begin{tabular}{|l|l|}
\hline When the following factors exist/increase... & $\ldots$ they are associated with \\
\hline Front door seating & Increased door crowding \\
\hline On two-door buses, middle door instead of back door & Increased door crowding \\
\hline \multirow{2}{*}{ Aisle length } & Decreased door crowding \\
\cline { 2 - 2 } Local bus service & Shorter marginal dwell time \\
\hline \multirow{3}{*}{ Door crowding } & Increased door crowding \\
\cline { 2 - 2 } & Shorter marginal dwell time \\
\hline & Longer marginal dwell time \\
\cline { 2 - 2 } & Riders hanging out the door \\
\cline { 2 - 2 } & Increased unsafe boarding and alighting \\
\cline { 2 - 2 } & Increased likelihood of stopping \\
\hline
\end{tabular}

at a greater rate than unsafe alightings because it is more difficult to alight from a crowded bus than it is to board it, due to the need to push through a large crowd.

One interesting aspect of the results is that local buses, despite causing increased door crowding, have shorter marginal dwell times than ticket buses. This indicates that local bus passengers' tendency to crowd the doorway is less of an issue in terms of dwell time than the need to process passengers carrying tickets. Thus, it is reasonable to conclude that service type has a larger role to play in affecting marginal dwell times than door crowding. Both service types, however, have increases in marginal dwell time when door crowding increases.

To reduce the negative effects of crowding, particular bus types could be operated. The optimal bus type would be a large two-door bus with a back door that does not have front seating, similar to bus type 4 in the study. This bus type is the least susceptible to the crowding that causes marginal dwell times to increase.

In addition to recommendations on bus design, we would offer that conductor training, while more difficult to implement, is also important. At low load factors, doorway crowding should be discouraged. In an environment like Bangladesh, where a conductor is always by the door, there should be an effort to train conductors and educate them on the dangers of crowding and how it affects passengers safety and operations. In any situation, door crowding should be discouraged, and an effort should be made to reduce the number of passengers by the door to improve performance. 
Conductors play a large role in keeping people from engaging in unsafe behavior. First, they can tell how crowded the bus is, and they have the power to prevent people from boarding a bus that is crowded. The conductor can help actively discourage people from hanging out the doors. It is recommended that conductors be made aware of the dangers of hanging out the door and monitor all doors carefully. The risks of EA, LA, EB, and LB must also be brought to conductors' attention, and there should be efforts made to discourage conductors from picking up or dropping off passengers mid-route. Crowded buses are associated with more $\mathrm{EB}$ and $\mathrm{LB}$, which may be due to conductors who are consciously trying to crowd buses and are actively seeking to pick up people between stops.

Reducing door crowding, unsafe boarding and alighting, and rolling through stops could be furthered through police enforcement. In Dhaka, bus operators already can be cited for using buses over a certain age and for improper fare pricing. Citing operators for visible violations of safe practices could increase the likelihood that the proposed conductor training is successful. It is expected that a conductor's knowledge of the negative effects of crowding are not enough to forgo crowding in order to maximize profit. In the areas that can be directly controlled, such as not allowing passengers to hang out the door, not rolling through stops, and preventing boarding and alighting when moving, monetary penalties could be implemented. If implemented, future research could measure the effect that training and enforcement have on door crowding.

The increase in dwell time caused by crowding is important for a transit operator to consider. Crowding on buses may be necessary in a system constrained by traffic congestion, but it must be recognized that crowding the door areas increases the operating time for a transit vehicle and creates unsafe situations for riders.

\section{Acknowledgments}

The authors would like to acknowledge the Fulbright Program, which provided the funding to study and research in Bangladesh and accomplished the data collection portion of this project. In addition, Dr. Md. Mizanur Rahman played a pivotal role in enabling the first author to arrange the initial project proposals and advise the study design and data collection research endeavors. Recognition is also given to Dr. Steve Polzin, who provided input at the beginning of the research. Partial funding for this project was provided through the National Science Foundation Graduate Research Fellowship. 


\section{References}

Aashtiani, H. Z., and H. Iravani. 2002. Application of dwell time functions in transit assignment model. Transportation Research Record 1817: 88-92.

Andaleeb, S. S., M. Haq, and R. I. Ahmed. 2007. Reforming innercity bus transportation in a developing country: A passenger-driven model. Journal of Public Transportation 10 (1): 1-25.

Dorbritz, R., M. Lüthi, U. Weidmann, and A. Nash. 2009. Effects of onboard ticket sales on public transport reliability. Transportation Research Record 2110: 112-119.

Dueker, K. J., T. J. Kimpel, J. G. Strathman, and S. Callas. 2004. Determinants of bus dwell time. Journal of Public Transportation 7 (1): 21-40.

Fernandez, R., P. Zegers, G. Weber, A. Figueroa, and N. Tyler. 2010. Platform height, door width and fare collection on public transport dwell time: A laboratory study. In 12th World Conference on Transport Research, 1-19.

Fernandez, R., and N. Tyler. 2005. Effect of passenger-bus-traffic interactions on bus stop operations. Transportation Planning and Technology 28(4): 273-292.

Fritz, M. S. 1983. Effect of crowding on light rail passenger boarding times. Transportation Research Record 908: 43-50.

Guenther, R. P., and K. S. Sinha. 1983. Modeling bus delays due to passenger boardings and alightings. Transportation Research Record 915: 7-13.

Hoque, M., and T. Hossain. 2004. Augmentation of mass transit mode in Dhaka, Bangladesh. In CODATU XI, Bucharest.

Katz, D., and M. M. Rahman. 2008. Overcrowded buses operating in Dhaka, Bangladesh and the effects on safety, performance, and comfort. Proceedings of the International Conference on Best Practices to Relieve Congestion on MixedTraffic Urban Streets in Developing Countries, ed. Murthy Bondada, 214-249. IIT Madras, Chennai, India.

Katz, D., and M. M. Rahman. 2010. Levels of overcrowding in bus system of Dhaka, Bangladesh. Transportation Research Record 2143: 85-91.

Kittelson \& Associates, KFH Group, Parsons Brinckerhoff Quade \& Douglas, and Hunter-Zaworski, K. 2003. Transit Capacity and Quality of Service Manual. 
Kogi, K. 1979. Passenger requirements and ergonomics in public transport. Ergonomics 22(6): 631-639.

Kraft, W. H., and T. F. Bergen. 1974. Evaluation of passenger service times for street transit systems. Transportation Research Record 505: 13-20.

Lin, T-M., and N. M. H. Wilson. 1992. Dwell time relationships for light rail systems. Transportation Research Record 1361: 287-295.

Perk, V., B. Thompson, and C. Foreman. 2001. Evaluation of first-year Florida MPO transit capacity and quality of service reports. Center for Urban Transportation Research, University of South Florida, Tampa.

Rajbhandari, R., S. Chien, and J. Daniel. 2003. Estimation of bus dwell times with automatic passenger counter information. Transportation Research Record 1841: 120-127.

Seattle Department of Transportation. 2007. UVTN monitoring project.

The Louis Berger Group. 2005. Strategic Transport Plan for Dhaka.

Zahir, U. M., H. Matsui, and M. Fujita. 2000. Investigate the effects of bus and passenger arrival patterns and service frequency on passenger waiting time and transit performance of Dhaka metropolitan area. Urban Transport and the Environment for the 21st Century, 55-64. Cambridge: MIT Press.

Zografos, K. G., and H. S. Levinson. 1986. Passenger service times for a no-fare bus system. Transportation Research Record 1051: 42-48.

\section{About the Authors}

DoNALD KATZ (dkatz@gatech.edu) is a third-year doctoral student in the School of Civil and Environmental Engineering at the Georgia Institute of Technology, performing research on domestic and international airline networks and airport systems. His master's thesis focused on the role airports and airlines play in connecting mega regions and the urban agglomerations that arise as metropolitan regions grow and blend borders, both internally and between one another. Previously, he spent one year on a Fulbright Scholarship in Dhaka, Bangladesh, developing a research project to study the effects of overcrowding in buses on the operation and safety of the bus and its riders. In 2010, he earned a National Science Foundation Graduate Research Fellowship to perform his research in aviation. In 2011, he was appointed an Eno Fellow and was awarded the Dr. Thomas D. Larson fellowship. Also 
in 2011, he earned an Airport Cooperative Research Program Graduate Research Award to conduct research on airline depeaking at hub airports and was awarded an Eisenhower fellowship, an Institute of Transportation Engineers (ITE) Georgia Section scholarship, and a scholarship to attend the Helsinki Summer School in Transportation in 2010.

Dr. LAURIE GARROW (laurie.garrow@ce.gatech.edu) is an Associate Professor in the School of Civil and Environmental Engineering at the Georgia Institute of Technology. Her research addresses the development and application of advanced models of travel demand that integrate discrete choice, econometric, and market research methods. She earned her Ph.D. in Civil Engineering at Northwestern University, with an emphasis on travel demand modeling and airline passenger behavior. Her work has been recognized via a NSF CAREER award and the CUTC-ARTBA New Faculty Member Award. 